\title{
A systematic review and meta-analysis of the long-term outcomes of ileal conduit and orthotopic neobladder urinary diversion
}

Eva Browne ${ }^{1}$; Nathan Lawrentschuk ${ }^{2}$; Niall F. Davis ${ }^{2}$

${ }^{1}$ Royal College of Surgeons, Dublin, Ireland; ${ }^{2}$ Department of Urology, The Austin Hospital, Victoria, Australia

Cite as: Can Urol Assoc J 2020 July 17; Epub ahead of print.

http://dx.doi.org/10.5489/cuaj.6466

Published online July 17, 2020

$* * *$

Abstract

Introduction: We aimed to perform a systematic review and meta-analysis on the long-term durability, incidence of complications, and patient satisfaction outcomes in ileal conduit (IC) and orthotopic neobladder (ONB).

Methods: A systematic electronic literature search was performed in Medline, Embase, Cochrane Library, and Scopus using MeSH and free-text search terms "Urinary diversion" AND "Ileal conduit" AND "Neobladder." The search concluded June 19, 2018. Inclusion criteria were those patients who had a cystectomy and required urinary diversion by either IC or neobladder.

Results: In total, 32 publications met the inclusion criteria. Data were available on 46787 patients ( $\mathrm{n}=36719$ for IC and $\mathrm{n}=10068$ for ONB). Meta-analyses showed that IC urinary diversions performed less favorably than ONB in terms of re-operation rates, Clavien-Dindo complications, and mortality rates; odds ratios (ORs) and 95\% confidence intervals (CIs) were $1.76(1.24,2.50) \mathrm{p}<0.01,1.16(1.09,1.22) \mathrm{p}<0.01$, and $6.29(5.30,7.48) \mathrm{p}<0.01$, respectively. IC urinary diversion performed better than ONB in relation to urinary tract infection rates and ureteric stricture rates, OR and 95\% CI $0.67(0.58,0.77) \mathrm{p}<0.01$ and $0.70(0.55,0.89) \mathrm{p}<0.01$, respectively.

Conclusions: Our results show that there is no significantly increased morbidity with ONB compared to IC. Selection of either urinary diversion technique should be based on factors such as tumor stage, comorbidities, surgical experience, and patient acceptance of postoperative sequalae. 


\section{Introduction}

There are many conditions which necessitate removal of the urinary bladder using cystectomy. ${ }^{1}$ The most common indication is cancer of the urinary bladder but in some cases cystectomy is indicated to treat benign disease such as interstitial cystitis. ${ }^{1}$ Cystectomy therefore requires replacement of the urinary bladder with a procedure known as urinary diversion. ${ }^{1}$ Urinary diversion is a form of urinary reconstruction and most commonly involves the use of a gastrointestinal (GI) segment to replace part or all of the function of the urinary bladder. ${ }^{1}$ An optimal bladder replacement should be able to hold large intravesical volumes whilst maintaining low pressure values in order to restore normal function and preserve the upper urinary tracts. ${ }^{1}$

Lifelong postoperative complications are common with any type of urinary diversion. ${ }^{1}$ These can be divided into three broad groups, (i) Metabolic complications which are due to the intestinal segment's resorptive capacity, (ii) Neuromechanical aspects which affect storage volume and diversion compliance and (iii) Technical-surgical complications which result in postoperative morbidity. ${ }^{1}$

Ileal conduit has long been considered the gold standard for replacement of the urinary bladder. However, orthotopic neobladder has a superior cosmetic appearance and better preservation of body image. ${ }^{2}$ The aim of this systematic review and meta-analysis is to perform a robust comparison of ileal conduit and orthotopic neobladder urinary diversion and to provide practitioners with a summary of the global trends for reconstructive preferences in urinary diversion.

\section{Methods}

\section{Search strategy}

This review was planned and reported in accordance with the Preferred Reporting Items for Systematic Reviews and Meta-Analyses (PRISMA). ${ }^{3}$

A systematic electronic literature search was carried out in Medline, Embase, Cochrane Library and Scopus. Using MeSH and free text terms, the search strategy was: "Urinary diversion" AND "Ileal conduit" AND "Neobladder". Titles and abstracts retrieved by the June 2018 search were screened independently by two authors (EB and ND), following the removal of duplicates. Where there was any uncertainty regarding inclusion, full texts were retrieved and assessed for inclusion. Excluded studies were listed with reasons given for their exclusion. Disagreements regarding the inclusion or exclusion of an article were resolved by discussion.

\section{Eligibility criteria}

Inclusion criteria were those patients who have had a cystectomy for any reason and required urinary diversion by either ileal conduit or orthotopic neobladder. Exclusion criteria were review articles, case reports, commentaries, letters, conference abstracts without sufficient outcome data and failure to meet the inclusion criteria. 


\section{Data extraction and outcomes}

The following data were extracted from each study: author's name, journal of publication, year of publication, country of origin, study type, total number of patients and patient demographics (age, sex, body mass index [BMI]). Information regarding the following outcomes were recorded from each eligible study. The primary outcome measures were quality of life, measures of longterm durability (including re-operation, urinary tract infections (UTI) and ureteric stricture), post-operative morbidity, post-operative mortality and length of stay. Secondary outcome measures were physiological changes including active reflux, mucous, upper tract dilatation/hydronephrosis, renal scarring, metabolic changes, urinary stones, and health economics.

\section{Statistical analysis}

Data were presented as a mean \pm SD for continuous variables. Differences between outcomes measured were considered significant at $\mathrm{p}<0.05$ (Stata). Meta-analysis was performed with Review Manager Version 5.3 software. ${ }^{4}$ The Mantel-Haenszel model was used for meta-analysis of dichotomous data and the inverse variance model for meta-analysis of continuous data. ${ }^{5}$

\section{Results}

\section{Eligible studies}

In total, 2907 articles were identified. Following the removal of duplicates ( $\mathrm{n}=1458), 1449$ articles were screened, of which 1417 were excluded as they did not meet the inclusion criteria. In total, 32 articles were included in the qualitative and quantitative analysis; see the PRISMA diagram in Figure 1 for the flow of studies through the review and the reasons for which studies were excluded.

Data were available for 46,787 patients in the studies included in this review $(n=36,719$ for ileal conduit and $n=10,068$ for orthotopic neobladders). Study characteristics are summarised in Table 1. In total there were 16 prospective case-control studies, ${ }^{6-21}$ one of which was a prospective case-control study with matched-pair analysis ${ }^{20}$ and 16 retrospective case-control studies. $^{22-36}$

Patient demographics (including patient age, male to female ratio and patient BMI) were reported, if available; these are outlined in Table 2 and Table 3. The mean patient age between the ileal conduit and orthotopic neobladder groups was significantly different, $69.65 \pm 5.84$ in the ileal conduit group versus $61.07 \pm 4.47$ in the orthotopic neobladder group, $95 \%$ Confidence Interval (CI) 8.44, 8.71, $\mathrm{p}<0.01$, with patients undergoing ileal conduit urinary diversion being older overall. The mean BMI of the ileal conduit and orthotopic neobladder groups were significantly different; $25.7 \pm 4.6$ in the ileal conduit group versus $23.7 \pm 3.3$ in the orthotopic neobladder group $95 \%$ CI $175,2.25, \mathrm{p}<0.01$. The sex ratio in both groups was significantly different (11:2 male:female in the ileal conduit group versus 11:1 male:female in the orthotopic neobladder group, $\mathrm{p}<0.01)$. 


\section{Primary outcomes}

\section{Quality of life}

Patient satisfaction, general measures of health status and disease specific measures of quality of life were not reported in a standardised manner across the studies. This precludes meaningful statistical analysis. Of the 32 included publications, 5 compared quality of life in patients with either diversion type. ${ }^{13} 18243435$ Using The European Organization for Research and Treatment of Cancer (EORTC) QLQ-C30 questionnaire, ${ }^{37}$ Navarro et al found a better acceptance in orthotopic neobladders versus ileal conduits. ${ }^{13}$ The scale used by the authors rates overall quality of life on a 7 point scale, where $1=$ Very Poor and $7=$ Excellent. ${ }^{37}$ Sogni et al. also used the QLQC30 questionnaire as well as the bladder cancer-specific module EORTC QLQ-muscle-invasive bladder cancer module 30 (BLM 30) ${ }^{38}$ and found that the quality of life reported in both groups was comparable but with a non-significant higher quality of life rating seen in the orthotopic neobladder group. ${ }^{34}$ Erber et al also used the QLQ-C30 questionnaire and reported overall quality of life as $58 \pm 25.3$ in the ileal conduit group and $72.3 \pm 19.5$ in the neobladder group. ${ }^{24}$ Sherwani et al used a simple satisfaction scale of "Very Good", "Good", "Poor" to compare quality of life between the two groups and reported higher ratings in the orthotopic neobladder group. ${ }^{18}$ Finally, Thulin et al had patients rate quality of life as "high", "moderate" or "low". 35 Of these, $68 \%$ of patients with an orthotopic neobladder reported their quality of life as "high" compared to $53 \%$ of ileal conduit recipients. ${ }^{35}$

\section{Measures of long-term durability}

The measures of long-term durability included in this review were re-operation rates, UTI rates and ureteric stricture rates. The meta-analysis of these outcomes are detailed in Figure 2.

Of the 32 studies included in this review, 9 examined re-operation rates. The rate of reoperation was significantly greater in patients with an ileal conduit compared to patients undergoing orthotopic neobladder formation [Odds Ratio (OR) 1.76: 95\% Confidence Interval (CI) 1.24, 2.50, p < 0.01)]; see Figure 2A.

The incidence of UTI rates was reported in 11 studies. The incidence of UTI was significantly less in patients with an ileal conduit versus patients with an orthotopic neobladder $[\mathrm{n}=1048 / 4013,26.1 \%$ versus $\mathrm{n}=433 / 1425,30.4 \%$ respectively, OR $0.67: 95 \%$ CI $0.58,0.77, \mathrm{p}$ $<0.01]$. This is reported in Figure 2B.

Ureteric stricture rates in both groups were reported in 9 publications. The incidence of the ureteric stricture was statistically less significant in patients undergoing ileal conduit urinary diversion versus patients with orthotopic neobladder, shown in Figure 2C [n=249/3533, 7.0\% versus $\mathrm{n}=109 / 1241,8.8 \%$ respectively, OR $0.70: 95 \%$ CI $0.55,0.89, \mathrm{p}<0.01]$.

\section{Complications}

Post-operative morbidity, reported in 21 publications, was described using the Clavien-Dindo classification in 12 publications. 67101415 19-22 26283339 . 
The incidence of post-operative morbidity was significantly higher in patients undergoing ileal conduit urinary diversion versus those undergoing orthotopic neobladder urinary diversion as shown in Figure 3A $[\mathrm{n}=15659 / 25264,61.9 \%$ versus $\mathrm{n}=5102 / 8478,60.1 \%$ respectively; OR $1.1695 \%$ CI 1.09, 1.22, $\mathrm{p}<0.01$ ]. Subgroup analysis of patients who suffered Clavien-Dindo 12 (minor) complications showed that patients undergoing ileal conduits were less likely to suffer a minor complication than those undergoing orthotopic neobladder urinary diversion, as shown in Figure 3B, this was not statistically significant $[n=1016 / 180256.4 \%$ versus $n=573 / 1029$, $55.7 \%$; OR $0.8995 \%$ CI 0.75, 1.06, p = 0.21]. Subgroup analysis of those who suffered ClavienDindo 3-5 (major) complications showed that patients with ileal conduits were significantly more likely to suffer a major complication than those with orthotopic neobladders, as shown in Figure $3 \mathrm{C}[\mathrm{n}=375 / 1802,20.8 \%$ versus $\mathrm{n}=184 / 1029,17.9 \%$; OR $1.2595 \%$ CI $1.02,1.53, \mathrm{p}=$ $0.03]$.

\section{Mortality}

Post-operative mortality was reported in 21 publications The mortality rate in patients with ileal conduit urinary diversion is significantly higher than that of patients undergoing orthotopic neobladder $[\mathrm{n}=3227 / 33656,9.6 \%$ versus $\mathrm{n}=142 / 8810,1.6 \%$; OR $6.2995 \%$ CI $5.30,7.48, \mathrm{p}<$ $0.01]$ as demonstrated in Figure 4.

\section{Length of stay}

Seven publications reported length of stay for ileal conduit and orthotopic neobladder groups as a mean \pm SD as outlined in Figure 5. Length of stay was shorter in the ileal conduit group compared to the orthotopic neobladder group $17.56 \pm 8.61$ days versus $19.93 \pm 7.85$ days with a mean difference of -0.74 [95\% CI $-1.30,-0.18, \mathrm{p}<0.01]$.

Eleven other publications reported length of stay as median and range and these are outlined in Table 4.

\section{Secondary outcomes}

\section{Physiological changes}

For the purpose of this review, physiological changes following urinary diversion were defined as: active reflux, upper tract dilation or hydronephrosis, mucous, metabolic changes urinary stones and renal scarring.

The incidence of active reflux was reported in 2 of the 32 included publications. The forest plot in Figure 6A shows that patients undergoing ileal conduit urinary diversion are at lower risk of active reflux than those undergoing orthotopic neobladder, this was not statistically significant $[\mathrm{n}=0 / 147$ versus $\mathrm{n}=1 / 81$ respectively; OR $0.1795 \%$ CI $0.01,4.31 \mathrm{p}=0.28]$. The incidence of upper tract dilatation/hydronephrosis was reported in 3 of the 32 included publications. Analysis shows that patients with ileal conduit urinary diversion are more likely to have hydronephrosis than those with orthotopic neobladders, shown in Figure 6B $[n=23 / 568$, 
$4.0 \%$ versus $n=9 / 297,3.0 \%$ respectively, OR $1.5695 \%$ CI $0.67,3.62, p=0.30$ ]; again, not statistically significant.

The incidence of mucous production was less in patients with ileal conduit than those with orthotopic neobladder $[\mathrm{n}=1 / 135,0.7 \%$ versus $\mathrm{n}=3 / 99,3 \%$ respectively; OR $0.5895 \% \mathrm{CI}$ $0.08,3.98, \mathrm{p}=0.58]$. This was not statistically significant. This is demonstrated in Figure $6 \mathrm{C}$. The incidence of metabolic change is less in patients with an ileal conduit versus orthotopic neobladder, shown in Figure 6D. [n $=26 / 2804.5 \%$ versus $n=37 / 330,11.2 \%$ respectively: OR $0.5795 \%$ CI $0.32,1.03, \mathrm{p}=0.06]$. This finding was not statistically significant

The incidence of urinary stones was lower in patients with ileal conduit urinary diversion compared to orthotopic neobladder $[n=167 / 4719,3.5 \%$ versus $n=85 / 1319,6.4 \%$ respectively; OR $0.4995 \%$ CI $0.37,0.64, \mathrm{p}<0.01]$. This is shown in Figure $6 \mathrm{E}$. This was statistically significant.

There were no data reported in any of the included studies regarding the incidence of renal scarring in patients with either urinary diversion.

\section{Health economics}

None of the studies included in this review examined or made any comment on the economic impact of either ileal conduit or orthotopic neobladder urinary diversion precluding a comparison of cost of intervention or assessment of cost-benefit relationship.

\section{Discussion}

This study is a comprehensive review comparing ileal conduit and orthotopic neobladder urinary diversions. The choice of urinary diversion has significant implications for both the patient in terms of their future health and quality of life and for the surgeon and their methods. The choice of which urinary diversion to use also depends on many factors such as surgical skill, urethral disease or patient acceptance. ${ }^{1}$ It is therefore imperative that a thorough comparison is made of the outcomes of IC and ONB to provide practitioners with a comprehensive summary of the data to aid surgical and patient decision making.

It demonstrates that there is an overall preference towards ileal conduit urinary diversion and a tendency for this type of diversion to be performed in older patients. It also showed a higher re-operation rate and rate of post-operative morbidity and mortality in those patients who underwent an ileal conduit urinary diversion. Orthotopic neobladder urinary diversions, however, performed worse in terms of UTI, ureteric stricture, urinary stone rates.

In this study, comparison of patient age in the two groups showed that patients IC urinary diversion were significantly older than those patients undergoing ONB diversion. It can be reliably assumed that older patients have greater comorbidities so interpretation of results may be affected by this finding. Younger patients, likely with fewer comorbidities, tend to have a ONB diversion, possibly due to the widely accepted belief that ONB has a greater risk of perioperative complications due to its technical complexity. ${ }^{2}$ This is therefore likely to confound data relating to post-operative complication rates in each group. The larger numbers of ileal conduits performed in these studies compared to orthotopic neobladders demonstrates the preference for 
ileal conduit as the choice of urinary diversion. This is likely to be multifactorial as addressed previously, including patient preference, surgical skill and other patient factors such as age or comorbidity.

From the included publications there was a better acceptance and quality of life in patients with orthotopic neobladder diversions than those with ileal conduit ${ }^{40}$. However it is worth bearing in mind that each type of urinary diversion has inherently different challenges associated with it. ${ }^{6}$ According to meta-analysis there is a higher rate of UTI in the orthotopic neobladder group, potentially as orthotopic neobladders often require self-catheterisation which comes with the associated risk of bacterial inoculation. ${ }^{35}$ Meta-analysis also demonstrated a significantly higher risk of ureteroileal stricture in patients with an orthotopic neobladder than those with an ileal conduit urinary diversion, possibly due to the use of an anti-reflux mechanism in ureterointestinal anastomosis, however an antireflux mechanism was only used for ONB in two of the publications included in this review. This highlights the importance of forming a low pressure reservoir. ${ }^{1}$

The studies included for analysis in this review focused predominantly on reporting perioperative data regarding ileal conduit urinary diversion and orthotopic neobladders, revealing a dearth of information on long-term outcomes of these two types of urinary diversion. This may explain the paucity of evidence relating to the long-term complications of urinary diversion. ${ }^{1}$ Meta-analysis of those publications which reported post-operative morbidity using ClavienDindo shows a significantly higher morbidity in ileal conduit compared to orthotopic neobladder. ${ }^{6710141519-22262833}$ This is potentially explained by noting that within this systematic review, patients undergoing ileal conduit tended to be older and have higher grade tumours, which may increase the risk of death independent of diversion type. It must also be considered that minor (CD 1-2) complications may be under reported given that many of the publications included in this review were retrospective case controls. ${ }^{27}$

Meta-analysis of mortality rates between ileal conduit and orthotopic neobladder urinary diversion showed a significantly increased risk of death in those patients undergoing ileal conduit diversion compared to patients with orthotopic neobladders. However, patients undergoing ileal conduit tend to be older and have higher grade tumours, which may increase the risk of death independent of diversion type. ${ }^{2}$

Meta-analysis of mean \pm SD of length of stay demonstrated a significantly longer length of stay in patients undergoing orthotopic neobladder. Length of stay is sometimes dependent on the practice of individual institutions and thus it cannot be assumed that orthotopic neobladder urinary diversion always results in an increased length of stay but it is still an important consideration when deciding which type of urinary diversion to use.

With the exception of stones (which were significantly more likely in orthotopic neobladder), meta-analysis of the physiological changes considered in this review showed no statistically significant results. Nonetheless, consideration of physiological changes such as hydronephrosis, vesicoureteric reflux, mucous production, metabolic changes and urinary stones 
is important when deciding between ileal conduit and orthotopic neobladder, particularly in patients with pre-existing conditions.

A cost-benefit comparison is a crucial aspect of assessing any intervention and there seems to be a complete lack of any such analysis in contemporary literature. This is certainly an aspect of urinary diversion which requires further study. In countries where universal or socialised healthcare does not exist, the type of urinary diversion a patient receives may depend on their ability to pay for this type. ${ }^{41}$

The main limitation of this meta-analysis is that the studies included for analysis consist of retrospective or prospective case-control studies. Other limitations include the small sample sizes contained within most publications, limiting the generalisability of the findings of this review and the non-standard reporting of outcomes. Thirdly, some data points were presented as median and range which precluded any analysis regarding these figures. Lastly, there is the potential for significant selection bias in all publications in that those undergoing orthotopic neobladder have lower stage tumours and would therefore have better postoperative outcomes in terms of recovery and mortality rates. ${ }^{20}$

However, this is a very robust analysis involving large numbers of patients with extensive follow up, using standardised questionnaires, and involves data from multiple institutions. This analysis also includes international publications and so is representative of global trends for reconstructive preferences in urinary diversion.

\section{Conclusions}

This systematic review and meta-analysis does not support the widely held perception that orthotopic neobladder is associated with increased risk of post-operative morbidity, however the reason for this may be multifactorial. Our findings demonstrated that orthotopic neobladder was associated with a lower rate of major (Clavien-Dindo 3-5) complications than the ileal conduit. However, larger cohort studies are required to reach a definitive conclusion as to which type of diversion is superior. Our results also reinforce that the selection of which type of urinary diversion to perform should be based on careful pre-operative counselling taking into account patient factors such as tumour stage and comorbidities, surgical skill and patient acceptance of the sequalae of either type of urinary diversion. 


\section{References}

1. Wein AJ, Kavoussi LR, Partin AW, et al. Campbell-Walsh urology. Philadelphia, PA: Elsevier 2016.

2. Gburek BM, Lieber MM, Blute ML. Comparison of Studer ileal neobladder and ileal conduit urinary diversion with respect to perioperative outcome and late complications. Journal of Urology 1998;160(3 I):721-23. doi: 10.1016/S0022-5347(01)62767-8

3. Moher D, Liberati A, Tetzlaff J, et al. Preferred reporting items for systematic reviews and meta-analyses: the PRISMA statement. Annals of internal medicine 2009;151(4):264-9, w64. [published Online First: 2009/07/23]

4. Review Manager (RevMan) [program]. 5.3 version. Copenhagen: The Nordic Cochrance Centre: The Cochrane Collaboration, 2014.

5. Davis NF, Quinlan MR, Poyet C, et al. Miniaturised percutaneous nephrolithotomy versus flexible ureteropyeloscopy: a systematic review and meta-analysis comparing clinical efficacy and safety profile. World journal of urology 2018;36(7):1127-38. doi: 10.1007/s00345-018-2230-x [published Online First: 2018/02/17]

6. Aboumarzouk OM, Drewa T, Olejniczak P, et al. Laparoscopic radical cystectomy: neobladder or ileal conduit, debate still goes on. Central European journal of urology 2014;67(1):9-15. doi: 10.5173/ceju.2014.01.art2 [published Online First: 2014/07/02]

7. Angulo JC, Caceres F, Cabrera PM, et al. Two-port laparoscopic radical cystectomy with reusable umbilical system: a feasibility study. Urology 2014;84(5):1088-93. doi: 10.1016/j.urology.2014.07.024 [published Online First: 2014/12/03]

8. Belotti S, Antonelli A, Bastiani N, et al. Role of urinary diversion on complication rate after radical cystectomy: Retrospective study on a single-centre cohort of 407 consecutive patients. Anticancer Research 2012;32(5):1917-19.

9. Collins JW, Tyritzis S, Nyberg T, et al. Robot-assisted radical cystectomy: description of an evolved approach to radical cystectomy. European urology 2013;64(4):654-63. doi: 10.1016/j.eururo.2013.05.020 [published Online First: 2013/06/19]

10. De Nunzio C, Cindolo L, Leonardo C, et al. Analysis of radical cystectomy and urinary diversion complications with the Clavien classification system in an Italian real life cohort. European journal of surgical oncology : the journal of the European Society of Surgical Oncology and the British Association of Surgical Oncology 2013;39(7):792-8. doi: 10.1016/j.ejso.2013.03.008 [published Online First: 2013/04/09]

11. Hofer M, Bhalani V, Kundu S, et al. Complications of cystectomy and urinary diversions from the national surgical quality improvement program. Journal of Urology 2012;187(4):e712. doi: 10.1016/j.juro.2012.02.1780

12. Jung JU, Sohn DW, Cho YH. Alteration in renal function for patients with ileal conduit and ileal orthotopic neobladder. Korean Journal of Urology 2006;47(10):1065-68.

13. Navarro M, Tagle R, Montes C, et al. Comparison of clinical factors, surgical complications, functional results and quality of life between four different urinary diversions. Urology 2013;82(3):S324.

14. Nazmy M, Wilson T, Yuh B, et al. Complications of robotic assisted radical cystectomy by diversion type. Journal of Urology 2013;189(4):e724. doi:

10.1016/j.juro.2013.02.2890

15. Nieuwenhuijzen JA, de Vries RR, Bex A, et al. Urinary diversions after cystectomy: the association of clinical factors, complications and functional results of four different 


\section{Comparison of ileal conduit and orthotopic neobladders}

diversions. European urology 2008;53(4):834-42; discussion 42-4. doi: 10.1016/j.eururo.2007.09.008 [published Online First: 2007/10/02]

16. Prcic A, Begic E. Complications After Ileal Urinary Derivations. Medical archives (Sarajevo, Bosnia and Herzegovina) 2017;71(5):320-24. doi:

10.5455/medarh.2017.71.320-324 [published Online First: 2017/12/30]

17. Roghmann F, Von Landenberg N, Schmidt J, et al. Evaluation of postoperative complications after radical cystectomy using the comprehensive complication index. Journal of Urology 2017;197(4):e722.

18. Sherwani Afak Y, Wazir BS, Hamid A, et al. Comparative study of various forms of urinary diversion after radical cystectomy in muscle invasive carcinoma urinary bladder. International journal of health sciences 2009;3(1):3-11. [published Online First: 2009/01/01]

19. Tan WS, Lamb BW, Tan MY, et al. In-depth Critical Analysis of Complications Following Robot-assisted Radical Cystectomy with Intracorporeal Urinary Diversion. European urology focus 2017;3(2-3):273-79. doi: 10.1016/j.euf.2016.06.002 [published Online First: 2017/07/30]

20. Antonelli A, Belotti S, Cristinelli L, et al. Comparison of Perioperative Morbidity of Radical Cystectomy With Neobladder Versus Ileal Conduit: A Matched Pair Analysis of 170 Patients. Clinical genitourinary cancer 2016;14(3):244-8. doi: 10.1016/j.clgc.2015.07.011 [published Online First: 2015/09/13]

21. Decaestecker K, Vanmarsnille T, Vandamme E, et al. Neobladder versus ileal conduit in Robot-Assisted Radical Cystectomy (RARC): Results from a high-volume academic centre. European Urology, Supplements 2016;15(7):227-28.

22. Abe T, Takada N, Shinohara N, et al. Comparison of 90-day complications between ileal conduit and neobladder reconstruction after radical cystectomy: a retrospective multi-institutional study in Japan. International journal of urology : official journal of the Japanese Urological Association 2014;21(6):554-9. doi: 10.1111/iju.12357 [published Online First: 2013/12/07]

23. Cho A, Lee SM, Noh JW, et al. Acid-base disorders after orthotopic bladder replacement: Comparison of an ileal neobladder and an ileal conduit. Renal Failure 2017;39(1):379-84. doi: 10.1080/0886022X.2017.1287733

24. Erber B, Schrader M, Miller K, et al. Morbidity and Quality of Life in Bladder Cancer Patients following Cystectomy and Urinary Diversion: A Single-Institution Comparison of Ileal Conduit versus Orthotopic Neobladder. ISRN urology 2012;2012:342796. doi: 10.5402/2012/342796 [published Online First: 2012/04/24]

25. Gore JL, Gilbert SM, Lai J, et al. Downstream consequences of urinary diversion. Journal of Urology 2010;183(4):e21-e22. doi: 10.1016/j.juro.2010.02.097

26. Kim SH, Yu A, Jung JH, et al. Incidence and risk factors of 30-day early and 90-day late morbidity and mortality of radical cystectomy during a 13-year follow-up: a comparative propensity-score matched analysis of complications between neobladder and ileal conduit. Japanese journal of clinical oncology 2014;44(7):677-85. doi: 10.1093/jjco/hyu051 [published Online First: 2014/05/06]

27. Mano R, Goldberg H, Stabholz Y, et al. Urinary Tract Infections After Urinary Diversion-Different Occurrence Patterns in Patients With Ileal Conduit and Orthotopic Neobladder. Urology 2018 doi: 10.1016/j.urology.2018.03.042 [published Online First: 2018/04/08] 
28. Monn MF, Kaimakliotis HZ, Cary KC, et al. Short-term morbidity and mortality of Indiana pouch, ileal conduit, and neobladder urinary diversion following radical cystectomy. Urologic Oncology: Seminars and Original Investigations 2014;32(8):1151-57. doi: 10.1016/j.urolonc.2014.04.009

29. Nahar B, Koru-Sengul T, Prakash NS, et al. Comparison of readmission and short-term mortality rates between different types of urinary diversion in patients undergoing radical cystectomy. Journal of Urology 2017;197(4):e726.

30. Parekh DJ, Gilbert WB, Koch MO, et al. Continent urinary reconstruction versus ileal conduit: a contemporary single-institution comparison of perioperative morbidity and mortality. Urology 2000;55(6):852-5. [published Online First: 2000/06/07]

31. Popov Z, Stavridis A, Lekovski L, et al. Urinary diversion: 30 years experience of a single centre in Republic of Macedonia. Acta chirurgica Iugoslavica 2007;54(4):49-55.

32. Roghmann F, Becker A, Trinh QD, et al. Updated assessment of neobladder utilization and morbidity according to urinary diversion after radical cystectomy: A contemporary US-population-based cohort. Canadian Urological Association journal = Journal de l'Association des urologues du Canada 2013;7(9-10):E552-60. doi: 10.5489/cuaj.221 [published Online First: 2013/09/27]

33. Roghmann F, Trinh QD, Braun K, et al. Standardized assessment of complications in a contemporary series of European patients undergoing radical cystectomy, International journal of urology : official journal of the Japanese Urological Association 2014;21(2):143-9. doi: 10.1111/iju.12232 [published Online First: 2013/08/03]

34. Sogni F, Brausi M, Frea B, et al. Morbidity and Quality of Life in Elderly Patients Receiving Ileal Conduit or Orthotopic Neobladder After Radical Cystectomy for Invasive Bladder Cancer. Urology 2008;71(5):919-23. doi: 10.1016/j.urology.2007.11.125

35. Thulin H, Steineck G, Kreicbergs U, et al. Hygiene and urinary tract infections after cystectomy in 452 Swedish survivors of bladder cancer. BJU international 2010;105(8):1107-17. doi: 10.1111/j.1464-410X.2009.08909.x [published Online First: 2009/10/30]

36. van Hemelrijck M, Thorstenson A, Smith P, et al. Risk of in-hospital complications after radical cystectomy for urinary bladder carcinoma: population-based follow-up study of 7608 patients. BJU international 2013;112(8):1113-20. doi: 10.1111/bju.12239 [published Online First: 2013/08/03]

37. Aaronson NK, Ahmedzai S, Bergman B, et al. The European Organization for Research and Treatment of Cancer QLQ-C30: a quality-of-life instrument for use in international clinical trials in oncology. Journal of the National Cancer Institute 1993;85(5):365-76. [published Online First: 1993/03/03]

38. Group EQoLS. EORTC QLQ - BLM30 1994.

39. Dindo D, Demartines N, Clavien P-A. Classification of Surgical Complications: A New Proposal With Evaluation in a Cohort of 6336 Patients and Results of a Survey. Annals of Surgery 2004;240(2):205-13. doi: 10.1097/01.sla.0000133083.54934.ae

40. Dutta SC, Chang SC, Coffey CS, et al. Health related quality of life assessment after radical cystectomy: comparison of ileal conduit with continent orthotopic neobladder. The Journal of urology 2002;168(1):164-7. [published Online First: 2002/06/07]

41. Moeen AM, Safwat AS, Gadelmoula MM, et al. Health related quality of life after urinary diversion. Which technique is better? Journal of the Egyptian National Cancer 
Institute 2018;30(3):93-97. doi: 10.1016/j.jnci.2018.08.001 [published Online First: 2018/08/27]

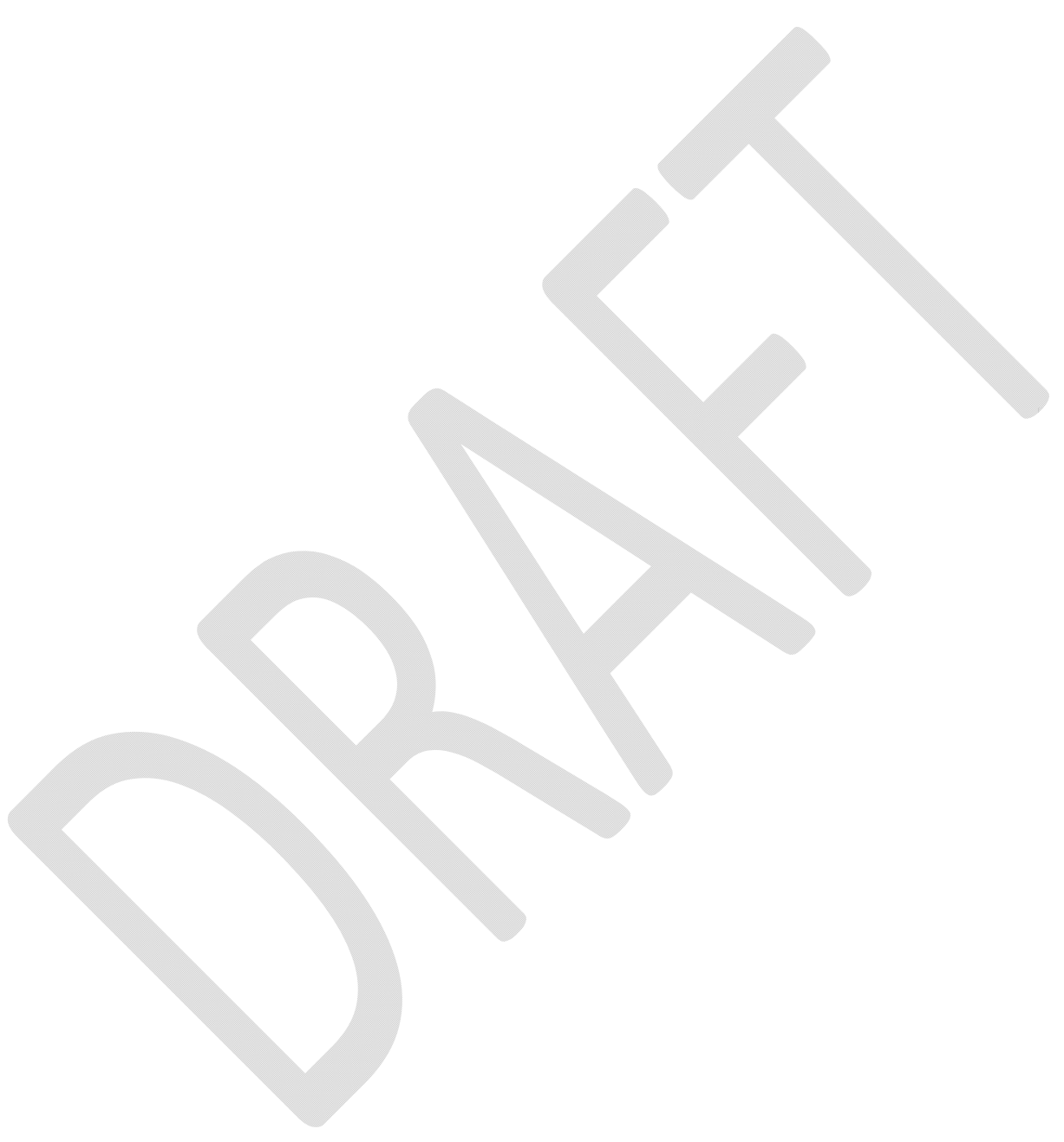




\section{Figures and Tables}

\section{Fig 1.}

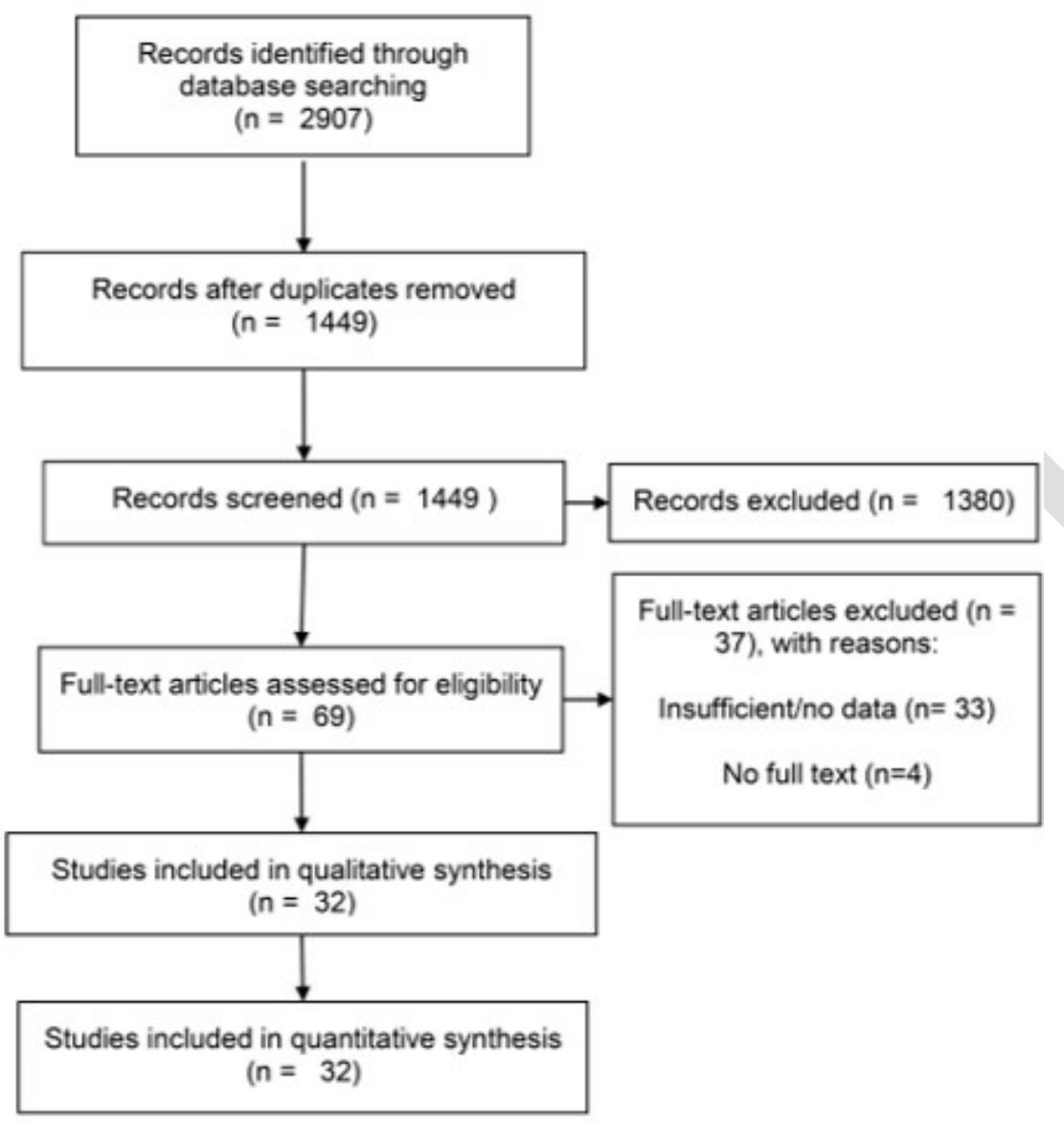


Fig 2.

A

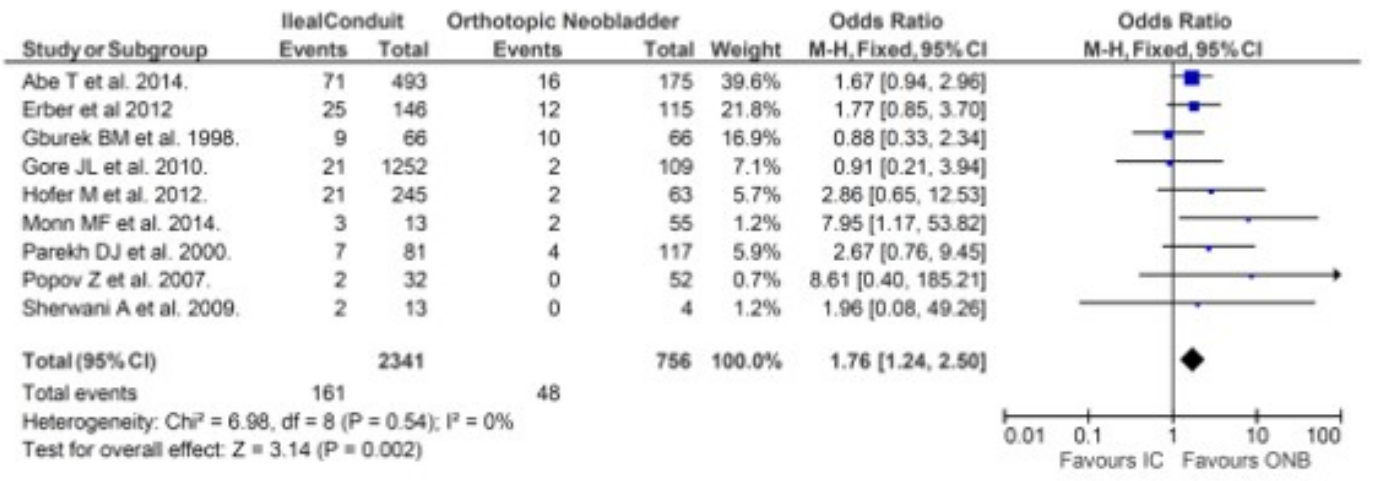

B

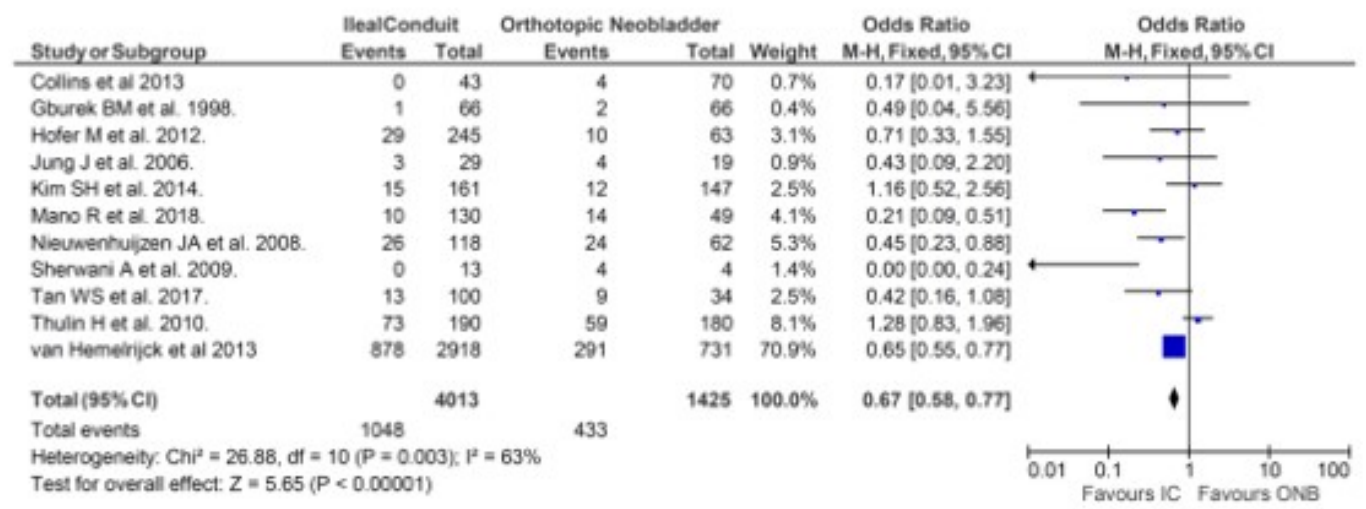

C

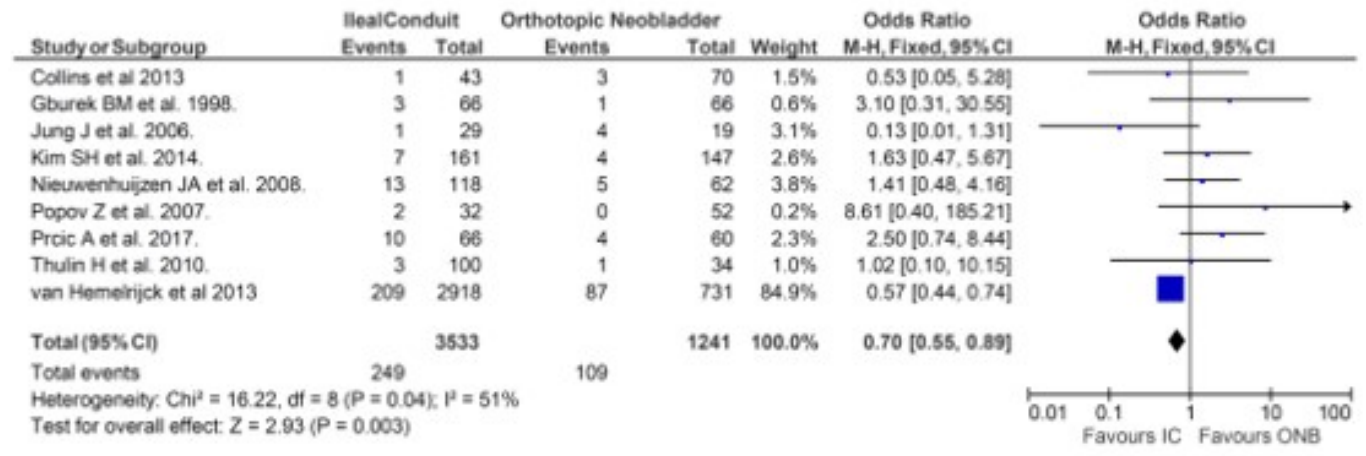


Fig 3.

A

\begin{tabular}{|c|c|c|c|c|c|c|c|c|c|}
\hline \multirow[b]{2}{*}{ shedger Subproup } & \multicolumn{2}{|c|}{ HearConait } & \multicolumn{2}{|c|}{ Orthotopic Nechlasder } & \multirow[b]{2}{*}{ Wegun } & \multirow{2}{*}{$\begin{array}{l}\text { Odds Ratio } \\
\text { Nat Fixed, } 25 \% \text { CI }\end{array}$} & \multirow{2}{*}{\multicolumn{3}{|c|}{$\begin{array}{c}\text { Oddis Rasio } \\
\text { M-C Fixed assicl }\end{array}$}} \\
\hline & Events & Total & Everits & Total & & & & & \\
\hline$A b e \mathrm{~T}$ at $a \mathrm{i} .2014$ & 350 & 493 & 129 & 175 & 236 & 0.8 10.92 .1291 & & & \\
\hline Abaumerzocik ON of al: 2014 . & 14 & 30 & 12 & 24 & $0.0 \%$ & $0.56[020.15 r]$ & & & \\
\hline Ang 100 ot $a 2014$ & 2 & E & 4 & 12 & ans & Det 1000.492 & & & \\
\hline Artionea A ef at 2016. & 54 & 45 & 52 & \$5 & ors & $140 \times 1273$ & & & \\
\hline Colles at.$x_{2013}$ & 45 & 43 & 55 & 70 & & Not esimatis & & & \\
\hline De Nente C $C$ ef al 2013 & 201 & 217 & 102 & 112 & $0.4 \mathrm{~s}$ & 12310542891 & & & \\
\hline Decanstecker $K$ ef al 2036 . & 30 & 40 & 3s & 32 & & Not esimatie & & & \\
\hline Erter et a 2012 & so1 & 140 & 30 & 115 & $19 \%$ & $0.501059+67$ & & - & \\
\hline Gore Jl at al 2010 & 827 & 1252 & 197 & 100 & & Not estrmatio & & & \\
\hline Holer Met at. 2012 & wot & 245 & 37 & $\omega$ & $0.0 \mathrm{x}$ & 1.501005 .2001 & & & \\
\hline Kins SHet a. 2014. & 78 & 161 & 7 & w7 & 0.25 & $12.60 ; 8.26 .42 .66 \mid$ & & & $\rightarrow$ \\
\hline Mtron of ex al 2014 . & 6 & 130 & 10 & 65 & Q.6\% & $181(1095.3 .47]$ & & & \\
\hline Navaro M et a. 2013. & 15 & 77 & s & 27 & Q.N & 0.91815 .5521 & & & \\
\hline Naxny M ot al za13 & 48 & 57 & 60 & 9t & ons & $08 t(0,32,185 \mid$ & & & \\
\hline Nevivemulasen JA at a 2008 & 87 & 118 & 100 & 62 & & Not eatmatio & & & \\
\hline poopiv $Z$ of at 2007 . & 20 & 32 & 26 & 52 & $0.3 \mathrm{~s}$ & 1879068.4 .091 & & & \\
\hline Rogtmam at an 2014 & 32 & 309 & $m$ & 166 & $0.6 \%$ & $13910022 \mathrm{mI}$ & & & \\
\hline Rogtmam f et at. 2013. & 16142 & 16702 & 2200 & 6220 & $91.8 \%$ & $13[1.07 .1 .19]$ & & & \\
\hline Sherwani A st al 2000 & e & 13 & 2 & 4 & ais & onsopar ar & & & \\
\hline Tou ws at al 2017 . & 120 & 100 & ti & is & & Noc estmatio & & & \\
\hline ven Henelifis of al 2013 & $29+2$ & zate. & $m$ & nit & & Not estriatis & & & \\
\hline Total (95) $\backslash$ CI) & & 25244 & & 3478 & $100.0 \%$ & $1.16[1.90,122]$ & & $t$ & \\
\hline & 15659 & & $\$ 102$ & & & & & & \\
\hline 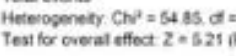 & $\begin{array}{l}4<P<0 \\
<0.0000\end{array}$ & $0001 x$ & & & & & 0102 of & 3 & $\frac{16}{10}$ \\
\hline
\end{tabular}

B

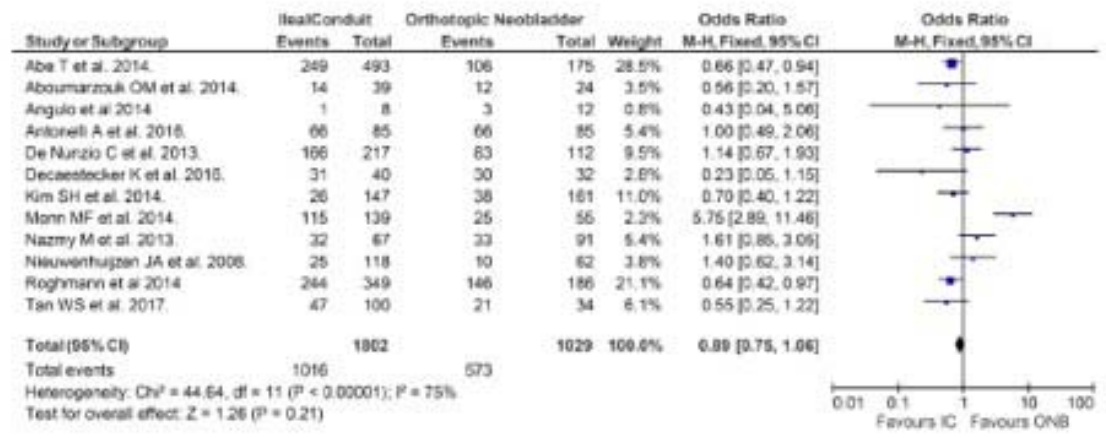

c

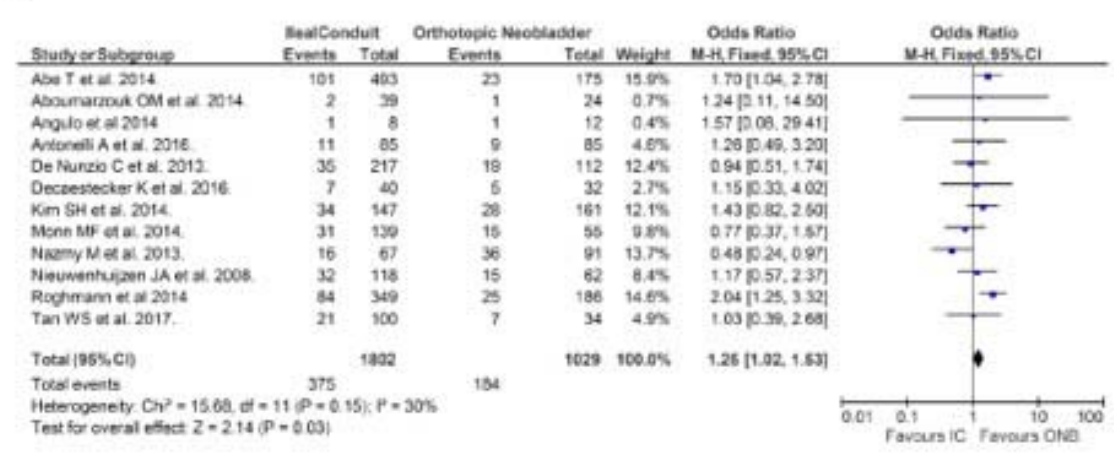


Fig 4.

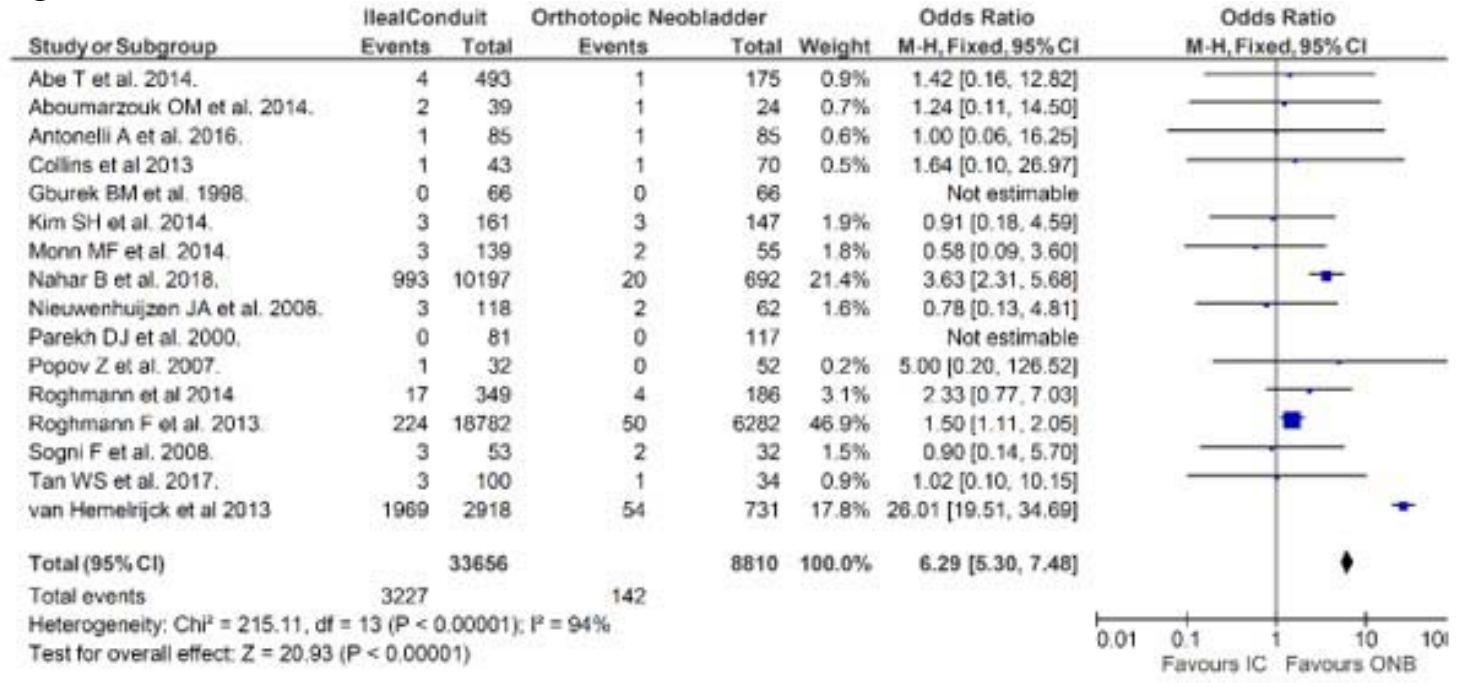

Fig 5.

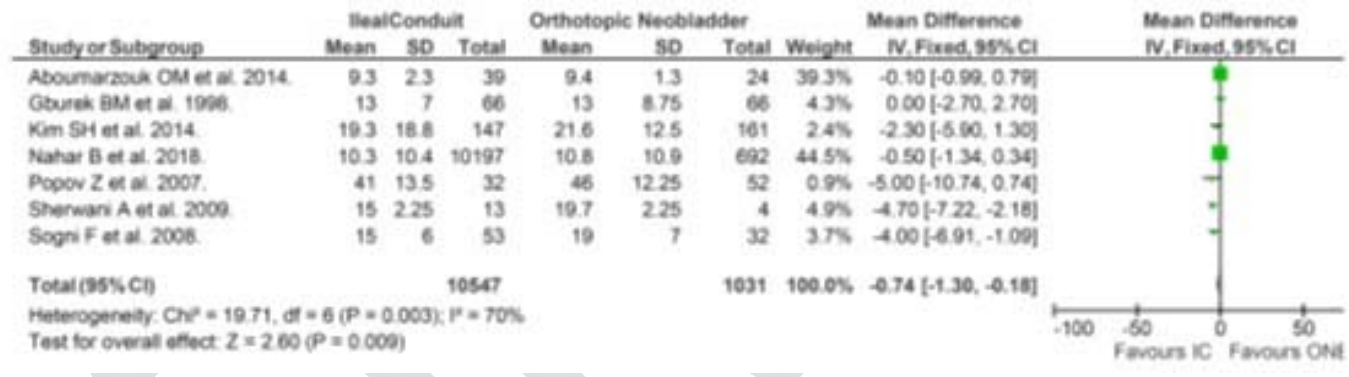


Fig. 6

A

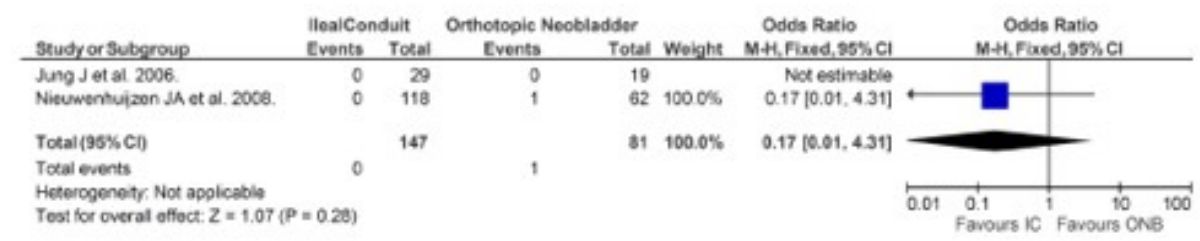

B

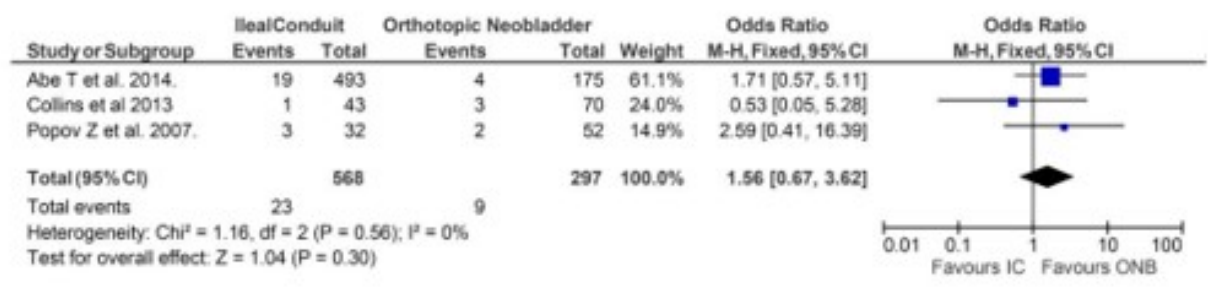

C

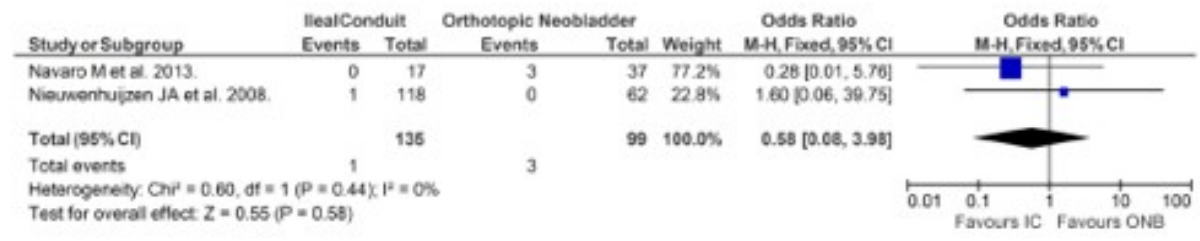

D

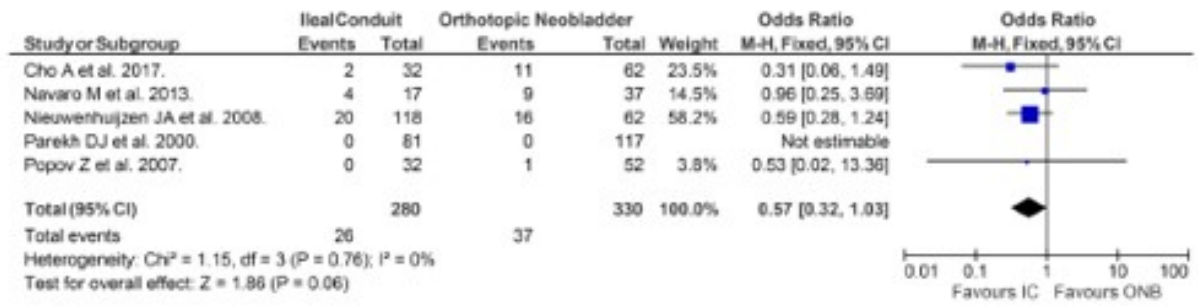

E

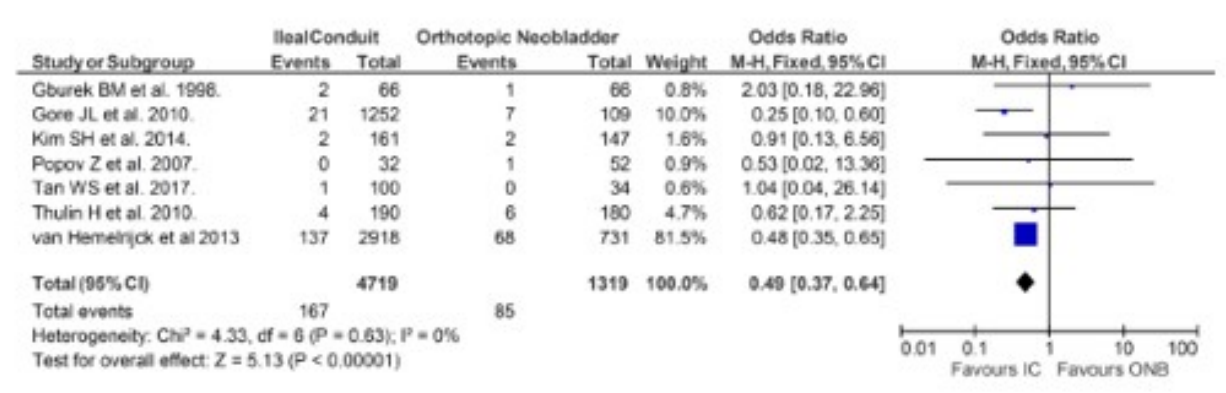


CUAJ - Review

Comparison of ileal conduit and orthotopic neobladders
Browne et al

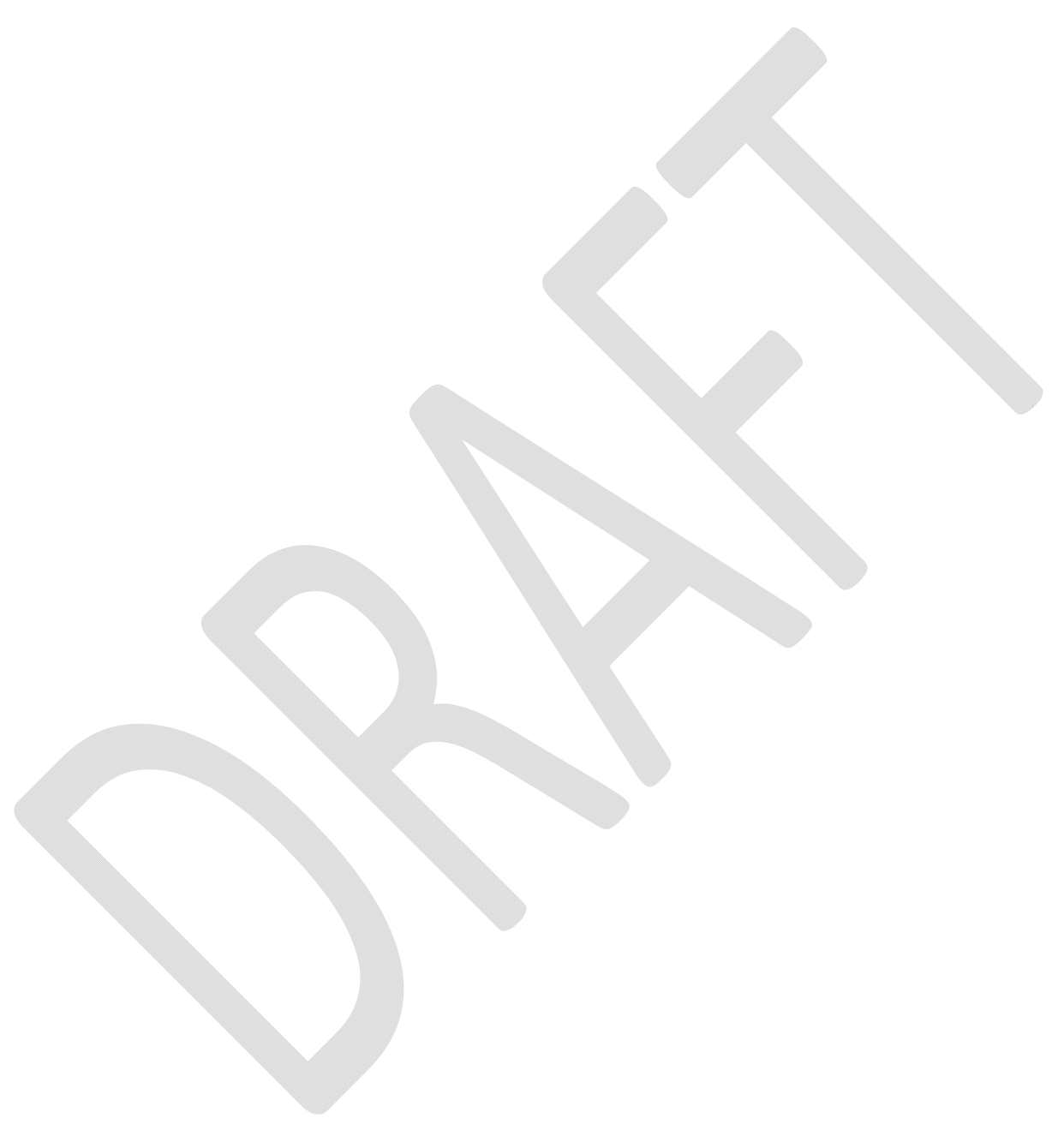


Comparison of ileal conduit and orthotopic neobladders

\begin{tabular}{|c|c|c|c|c|c|c|}
\hline Author (year) & Origin & Journal & $\begin{array}{c}\text { Type of } \\
\text { study }\end{array}$ & $\begin{array}{l}\text { Level of } \\
\text { evidence }\end{array}$ & IC $(N)$ & $\begin{array}{c}\text { ONB } \\
(\mathrm{N})\end{array}$ \\
\hline Abe et al, 2014 & Japan & Int J Urol & $\mathrm{RCC}$ & $3 b$ & 493 & 175 \\
\hline Aboumarzouk et al, 2014 & Poland & Cent European J Urol & PCC & $3 b$ & 39 & 24 \\
\hline Angulo et al, 2014 & Spain & Urology & PCC & $3 b$ & 8 & 12 \\
\hline Antonelli et al 2016 & Italy & Clin Genitourin Cancer & PCC & $3 b$ & 85 & 85 \\
\hline Belotti et al, 2012 & Italy & Anticancer Research & PCC & $3 b$ & 223 & 111 \\
\hline Cho et al, 2017 & Korea & Renal Failure & $\mathrm{RCC}$ & $3 b$ & 33 & 62 \\
\hline Collins et al, 2013 & Sweden & Eur Urol & PCC & $3 b$ & 43 & 70 \\
\hline De Nunzio et al, 2013 & Italy & Eur J Surg Oncol & PCC & $3 b$ & 217 & 112 \\
\hline Decaestecker et al, 2016 & Belgium & European Urology, Supplements & PCC & $3 b$ & 40 & 32 \\
\hline Erber et al, 2012 & Germany & IRSN Urol & $\mathrm{RCC}$ & $3 \mathrm{~b}$ & 23 & 34 \\
\hline Gburek et al, 1998 & USA & Journal of Urology & $\mathrm{RCC}$ & $3 b$ & 66 & 66 \\
\hline Gore et al, 2010 & USA & Journal of Urology & $\mathrm{RCC}$ & $3 \mathrm{~b}$ & 1252 & 109 \\
\hline Hofer et al, 2012 & USA & Journal of Urology & PCC & $3 \mathrm{~b}$ & 245 & 63 \\
\hline Jung et al, 2006 & Korea & Korean Journal of Urology & PCC & $3 b$ & 29 & 19 \\
\hline Kim et al, 2014 & Korea & Jpn J Clin Oncol & RCC & $3 b$ & 161 & 147 \\
\hline Mano et al, 2018 & Israel & Urology & $\mathrm{RCC}$ & $3 \mathrm{~b}$ & 130 & 49 \\
\hline Monn et al, 2014 & USA & $\begin{array}{c}\text { Urologic Oncology: Seminars and Original } \\
\text { Investigations }\end{array}$ & $\mathrm{RCC}$ & $3 b$ & 139 & 55 \\
\hline Nahar et al, 2018 & USA & Journal of Urology & $\mathrm{RCC}$ & $3 \mathrm{~b}$ & 10197 & 692 \\
\hline Navarro et al, 2008 & Chile & Urology & PCC & $3 b$ & 17 & 37 \\
\hline Nazmy et al, 2013 & USA & Journal of Urology & PCC & $3 b$ & 67 & 91 \\
\hline Nieuwenhuijzen et al, 2008 & The Netherlands & Eur Urol & PCC & $3 b$ & 118 & 62 \\
\hline
\end{tabular}


Comparison of ileal conduit and orthotopic neobladders

\begin{tabular}{|c|c|c|c|c|c|c|}
\hline Parekh et al, 2000 & USA & Urology & $\mathrm{RCC}$ & $3 b$ & 81 & 117 \\
\hline Popov et al, 2007 & $\begin{array}{l}\text { Republic of } \\
\text { Macedonia }\end{array}$ & Acta chirurgica lugoslavica & $\mathrm{RCC}$ & $3 b$ & 32 & 52 \\
\hline Prcic et al, 2017 & $\begin{array}{l}\text { Bosnia and } \\
\text { Herzegovina }\end{array}$ & Med Arch & PCC & $3 b$ & 66 & 60 \\
\hline Roghmann et al, 2013 & USA & Can Urol Assoc J & $\mathrm{RCC}$ & $3 b$ & 18782 & 6282 \\
\hline Roghmann et al, 2014 & Germany & Int J Urol & $\mathrm{RCC}$ & $3 b$ & 349 & 186 \\
\hline Sogni et al, 2008 & Italy & Urology & $\mathrm{RCC}$ & $3 b$ & 53 & 32 \\
\hline Tan et al, 2017 & United Kingdom & Eur Urol Focus & PCC & $3 b$ & 100 & 34 \\
\hline Thulin et al, 2010 & Sweden & BJU Int & $\mathrm{RCC}$ & $3 b$ & 190 & 180 \\
\hline van Hemelrijck et al, 2013 & Sweden & BJU Int & $\mathrm{RCC}$ & $3 b$ & 2918 & 720 \\
\hline
\end{tabular}

IC: ileal conduit; ONB: orthotopic neobladder; PCC: prospective case-control; RCC: retrospective case-control. 


\begin{tabular}{|l|c|c|c|c|c|c|}
\hline Table 2. Patient demographics from papers where age was reported as a mean \pm standard deviation \\
\hline Author (year) & Age (conduit) & $\begin{array}{c}\text { Age } \\
\text { (neobladder) }\end{array}$ & $\begin{array}{c}\text { Male/female } \\
\text { (conduit) }\end{array}$ & $\begin{array}{c}\text { Male/female } \\
\text { (neobladder) }\end{array}$ & $\begin{array}{c}\text { BMI } \\
\text { (conduit) }\end{array}$ & $\begin{array}{c}\text { BMI } \\
\text { (neobladder) }\end{array}$ \\
\hline Aboumarzouk et al, 2014 & $60 \pm 7.11$ & $57 \pm 8.68$ & $34 / 5$ & $24 / 0$ & $27.2 \pm 2.3$ & $27.96 \pm 2$ \\
\hline Antonelli A et al 2016 & $63 \pm 8.8$ & $63.5 \pm 6.7$ & $69 / 16$ & $72 / 13$ & NR & NR \\
\hline Belotti et al, 2012 & $70.4 \pm 8.1$ & $60.6 \pm 0.9$ & $183 / 34$ & $90 / 21$ & $26.3 \pm 4.3$ & $26.3 \pm 3.6$ \\
\hline Cho et al, 2017 & $69.5 \pm 8.1$ & $64.5 \pm 8.6$ & $23 / 10$ & $52 / 10$ & NR & NR \\
\hline Collins et al, 2013 & $69.9 \pm 6.7$ & $59.8 \pm 9.0$ & $31 / 11$ & $62 / 8$ & $24.8 \pm 3.1$ & $26.1 \pm 3.4$ \\
\hline De Nunzio et al, 2013 & $71 \pm 9.75^{*}$ & $63 \pm 0.25^{*}$ & $\mathrm{NR}$ & $\mathrm{NR}$ & $26.4 \pm 6^{*}$ & $25 \pm 3.25^{*}$ \\
\hline Decaestecker et al, 2016 & $71 \pm 1.5^{*}$ & $63 \pm 1.25^{*}$ & $29 / 11$ & $27 / 5$ & $26 \pm 4.25^{*}$ & $26 \pm 3.75^{*}$ \\
\hline Gburek B et al, 1998 & $69 \pm 11.75^{*}$ & $62 \pm 12.75^{*}$ & $66 / 0$ & $62 / 4$ & $\mathrm{NR}$ & $\mathrm{NR}$ \\
\hline Hofer et al, 2012 & $69.7 \pm 3.75^{*}$ & $59.7 \pm 15$ & $\mathrm{NR}$ & $\mathrm{NR}$ & $\mathrm{NR}$ & $\mathrm{NR}$ \\
\hline Jung et al, 2006 & $65.6 \pm 9.9$ & $60.8 \pm 8.3$ & $\mathrm{NR}$ & $\mathrm{NR}$ & $\mathrm{NR}$ & $\mathrm{NR}$ \\
\hline Kim et al, 2014 & $67.1 \pm 8.9$ & $59.4 \pm 9.4$ & $115 / 32$ & $156 / 5$ & $23.6 \pm 3.3$ & $24 \pm 3.1$ \\
\hline Monn et al, 2014 & $72.6 \pm 10$ & $59.6 \pm 9$ & $107 / 32$ & $49 / 6$ & $\mathrm{NR}$ & $\mathrm{NR}$ \\
\hline Nahar et al, 2018 & $68.8 \pm 10.1$ & $62.8 \pm 10$ & $8835 / 1362$ & $663 / 29$ & $\mathrm{NR}$ & $\mathrm{NR}$ \\
\hline Parekh et al, 2000 & $68 \pm 12.75^{*}$ & $60 \pm 13.5^{*}$ & $48 / 33$ & $97 / 20$ & $\mathrm{NR}$ & $\mathrm{NR}$ \\
\hline Roghmann et al, 2013 & 69.6 & 60.8 & $81 / 19$ & $91 / 9$ & $\mathrm{NR}$ & $\mathrm{NR}$ \\
\hline Sherwani et al, 2009 & 59 & 53.3 & $\mathrm{NR}$ & $\mathrm{NR}$ & $\mathrm{NR}$ & $\mathrm{NR}$ \\
\hline Thulin et al, 2010 & 70.1 & 64.3 & $134 / 56$ & $165 / 15$ & $\mathrm{NR}$ & $\mathrm{NR}$ \\
\hline
\end{tabular}

*Estimated standard deviation based on the Range Rule of Thumb. BMI: body mass index; NR: not reported. 
Comparison of ileal conduit and orthotopic neobladders

\begin{tabular}{|l|c|c|c|c|c|c|}
\hline Table 3. Patient demographics from papers where age was reported as a median and range \\
\hline Author (year) & Age (conduit) & Age (neobladder) & $\begin{array}{c}\text { Male/female } \\
\text { (conduit) }\end{array}$ & $\begin{array}{c}\text { Male/female } \\
\text { (neobladder) }\end{array}$ & BMI (conduit) & BMI (neobladder) \\
\hline Abe et al, 2014 & $70(37-89)$ & $63(25-86)$ & $364 / 129$ & $164 / 11$ & $23(14.6-35.1)$ & $23.3(16-31.5)$ \\
\hline Angulo et al, 2014 & $74.5(70-82.2)$ & $66(61.5-75)$ & $5 / 3$ & $12 / 0$ & $27.7(23.2-31.8)$ & $27.3(25.5-28.5)$ \\
\hline Erber et al, 2012 & $70(64-75)$ & $62(56-66)$ & $98 / 48$ & $110 / 5$ & NR & NR \\
\hline Mano et al, 2018 & $72(65-78)$ & $60(53-65)$ & $112 / 18$ & $43 / 6$ & NR & NR \\
\hline $\begin{array}{l}\text { Nieuwenhuijzen et al, } \\
2008\end{array}$ & $70(46-85)$ & $62(32-73)$ & $88 / 30$ & $59 / 3$ & NR & NR \\
\hline Roghmann et al, 2014 & $72(67-76)$ & $61(55-67)$ & $256 / 93$ & $158 / 28$ & $27.3(24.6-29.8)$ & $26.1(23.8-29.2)$ \\
\hline Sogni et al, 2008 & $78.9(75-88)$ & $77.5(75-82)$ & NR & NR & NR & NR \\
\hline Tan et al, 2017. & $67.4(60.4-74.3)$ & $54.5(48.6-61.6)$ & $75 / 25$ & $28 / 6$ & $27.2(23.4-31)$ & $27.3(23-28.5)$ \\
\hline
\end{tabular}

BMI: body mass index; NR: not reported. 
CUAJ - Review

al

Comparison of ileal conduit and orthotopic

Browne et

neobladders

Table 4. Studies where length of stay is reported as median and range

\begin{tabular}{|l|c|c|c|c|}
\hline \multirow{2}{*}{ Author (year) } & \multicolumn{2}{|c|}{ Ileal conduit } & \multicolumn{2}{c|}{ Orthotopic neobladder } \\
\cline { 2 - 5 } & $\mathbf{n}$ & $\begin{array}{c}\text { Median } \\
\text { (range) }\end{array}$ & $\mathbf{n}$ & $\begin{array}{c}\text { Median } \\
\text { (range) }\end{array}$ \\
\hline Abe et al, 2014 & 493 & $39(3-257)$ & 175 & $42(18-364)$ \\
\hline Angulo et al, 2014 & 8 & $9.5(8-11)$ & 12 & $8.5(7.2-10.7)$ \\
\hline Antonelli et al, 2016 & 85 & 17 & 85 & 21 \\
\hline Belotti et al, 2012 & 223 & $20(16-24)$ & 111 & $24(20-29)$ \\
\hline Collins et al, 2013 & 43 & $9(6-142)$ & 70 & $9(4-78)$ \\
\hline Decaestecker et al, 2016 & 40 & $10(5-36)$ & 32 & $11(6-39)$ \\
\hline Monn et al, 2014 & 139 & $8(6-10)$ & 55 & $7(6-8)$ \\
\hline Nieuwenhuijzen et al, 2008 & 118 & $17(6-53)$ & 62 & $15(8-44)$ \\
\hline Parekh et al, 2000 & 81 & $8(5-60)$ & 117 & $7(5-28)$ \\
\hline Roghmann et al, 2014 & 349 & $19(16-24)$ & 70 & $9(17-23)$ \\
\hline Tan et al, 2017 & 100 & $10(8-15.5)$ & 34 & $11(8.5-14)$ \\
\hline
\end{tabular}

